\title{
THE ACTIVITIES OF THE TOMSK DEPARTMENT OF THE SOCIETY FOR THE DISSEMINATION OF EDUCATION AMONG JEWS IN RUSSIA DURING THE FIRST WORLD WAR
}

\author{
Ksenia A. Tishkina \\ Siberian Federal University. Krasnoyarsk, Russia. Email: ksetishkina[at]mail.ru
}

\begin{abstract}
The article examines the activities of the Tomsk department of the Society for the Spread of Education among Jews in Russia (SEJ) during the First World War. The aim of the study is to comprehensively consecrate the main vectors of the work of the members of the Tomsk SEJ in the context of the global cataclysm. Based on the involvement of a wide range of sources, the article describes the cultural, educational and charitable areas of the department's work. The organization was financed primarily by private donations received from the representatives of the Jewish communities of Siberia through holding charitable events and returning student loans. As a result of the scientific research, it was concluded that the peak of the activity of the Tomsk department of the SEJ was during the war years. The society had to adapt to the realities of wartime, while at the same time accomplishing the main goal of the organization - spreading education among the Jewish population. For a long time being the only SEJ representative in Siberia, the Tomsk department managed to take an honorable place among the educational organizations of the region. Under the influence of the refugee and social movement, the representatives of other Jewish institutions began to appear in Tomsk, which most often consisted of the same people. However, the Tomsk department of the SEJ has managed to maintain its importance and relevance.
\end{abstract}

\section{Keywords}

Jews; World War I; Siberia; Tomsk; Tomsk Province; Refugees; Education; Children's Summer Colonies; School; Lectures 


\section{ДЕЯТЕЛЬНОСТЬ ТОМСКОГО ОТДЕЛА ОБЩЕСТВА ПО РАСПРОСТРАНЕНИЮ ПРОСВЕЩЕНИЯ МЕЖДУ ЕВРЕЯМИ В РОССИИ В ГОДЫ ПЕРВОЙ МИРОВОЙ ВОЙНЫ}

\section{Тишкина Ксения Алексеевна}

Сибирский федеральный университет. Красноярск, Россия. Email: ksetishkina[at]mail.ru

\section{Аннотация}

В статье рассматривается деятельность Томского отдела Общества распространения просвещения между евреями в России (ОПЕ) в годы Первой мировой войны. Целью исследования является всестороннее освещение основных векторов работы членов Томского ОПЕ в условии мирового катаклизма. На основании привлечения широкого круга источников охарактеризованы культурно-просветительные и благотворительные направления работы отдела. Финансирование организации осуществлялось преимущественно за счет частных пожертвований представителей еврейских общин Сибири; проведения благотворительных мероприятий, возвращения денежных ссуд за обучение. В результате научного исследования сделан вывод, что на годы войны выпал пик деятельности Томского отдела ОПЕ. Обществу приходилось подстраиваться под реалии военного времени, осуществляя главную цель организации - распространение просвещения среди еврейского населения. Будучи долгое время единственным представителем ОПЕ в Сибири, Томский отдел сумел занять почетное место среди просветительских организаций региона. Под влиянием беженского и общественного движения в Томске стали появляться представительства иных еврейских учреждений. Чаще всего в их состав входили одни и те же люди. Однако Томский отдел ОПЕ сумел сохранить свою значимость и востребованность.

Ключевые слова

евреи; Первая мировая война; Сибирь; Томск; Томская губерния; беженцы; просвещение; детские летние колонии; школа; лекции

Это произведение доступно по лицензии Creative Commons «Attribution» («Атрибуция») 4.0 Всемирная 


\section{ВВЕДЕНИЕ}

Законодательная политика Российской империи в отношении евреев четко регулировала их положение, права и полномочия: долгое время действовали ограничения как в передвижении по территории Российской империи, так и в получении образования, трудоустройстве. В период «великих реформ» Александра II начался процесс значительного облегчения положения еврейского населения. 27 ноября 1861 г. было издано высочайше утверждённое мнение Государственного совета «О преимуществах евреев, получивших высшее образование, а равно служащих при еврейских учебных заведениях», согласно которому некоторые категории еврейского населения получали права проживания вне черты оседлости. В ноябре 1864 г. был издан высочайше утверждённый «Устав Гимназий и Прогимназий ведомства Министерства народного Просвещения», дающий право на обучение всем лицам - вне зависимости от их национальности и религиозных предпочтений (Егоров, 2013, с. 54).

Идея об открытии общественной организации просветительского толка, которая могла бы объединить евреев Российской империи, возникла в 1860 г. в Санкт-Петербурге и Одессе с подачи писателя О. А. Рабиновича. Тогда же был разработан Устав будущей организации. В 1862 г. вышел рескрипт, давший толчок к развитию общественного движения в Российской империи. Согласно документу, разрешение на открытие частной благотворительной организации можно было получить у представителей государственной власти (Абросимова, 1992, с. 90). В 1863 г. с разрешения министра внутренних дел графа П.А. Валуева был утвержден Устав «Общества для распространения просвещения между евреями в России» (ОПЕ). Как отмечала исследовательница Е. А. Дельцева, ОПЕ являлось ярким примером общественной организации, в которой сошлись «...разные векторы идентификации - профессиональный, национальный, религиозный, политический <...>, социальный...» (Дегальцева, 2006, с. 88).

Учредителями ОПЕ выступили известные общественные деятели финансист Е. Г. Гинцбург и промышленник А. М. Бродский. Целью деятельности организации являлось «...распространение просвещения между евреями, проживающими в России, поощрение литературы и доставление пособий учащемуся юношеству» (Устав..., 1896, с. 1). Кроме этого общество брало на себя обязательство содействовать в обучении евреев русскому языку, а также осуществлять издательскую деятельность на русском и еврейском. С 1910 г. ОПЕ имело свой печатный орган - журнал «Вестник Общества распространения 
просвещения между евреями в России», который издавался на русском языке с приложением на древнееврейском и разговорно-еврейском языках.

В разные годы в Устав организации вносились изменения касательно реализации основной цели ОПЕ. Окончательный документ был сформирован в 1908 г., после вступления в силу Указа «О временных правилах об обществах и союзах» (1906 г.). Помимо издательской деятельности общество взяло обязательство по открытию для еврейского населения Российской империи учебных заведений, библиотек, музеев и т.д.; занималось сбором информации о состоянии просвещения в стране; оказанием разнообразной помощи еврейским учебным заведениям, учащимся и педагогам. Финансирование организации осуществлялось за счет членских взносов, частных пожертвований и средств, получаемых от продажи изданий общества. Первоначально минимальный размер членского взноса составлял 25 руб., в 1908 г. - 3 руб. Это способствовало привлечению широкого круга населения для вступления в состав членов организации. В новых редакциях Устава подчеркивалось, что членом ОПЕ мог стать желающий «..без различия вероисповедания» (Устав, 1908, с. 2). Если в ОПЕ вступал известный ученый, который мог бы оказывать содействие в продвижении интересов организации, то обязательства по выплате ежегодных членских взносов на него не распространялись.

Еще в 1867 г. ОПЕ было получено разрешение на открытие в городах Российской империи отделов организации. Одним из условий их создания являлось наличие 25 человек, постоянно проживающих в населенном пункте и готовых вступить в ОПЕ. Первое отделение было открыто в Одессе (Кнорринг, 2005, с. 21). К концу 1913 г. в Российской империи действовало 32 отделения организации. Количество членов ОПЕ составляло 7000 чел. (на 1911 г.).

\section{ИСТОРИОГРАФИЧЕСКИЙ ОБЗОР}

Изучению культурно-просветительского движения евреев в Сибири посвящен ряд научных работ.

Исследовательница О.С. Ульянова в монографии «Еврейское население в экономической, социокультурной и общественно-политической жизни города Томска (вторая половина XIX - 20-е гг. XX столетия)» (2010) свидетельствовала о высокой активности еврейской общины, деятельность которой была направлена на удовлетворение социальных и культурных потребностей местных евреев.

В коллективной монографии Е. А. Белых, Л. В. Кальминой и Л. В. Курас «Общественная и культурно-просветительская деятель- 


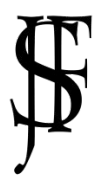

Журнал Фронтирных Исследований. 2021. No 4 | ISSN: 2500-0225

Этнические меньшинства в контактных зонах | Doi: https://doi.org/10.46539/jfs.v6i4.343

ность евреев в Забайкальской области (60-е гг. XIX в. - февраль 1917 г.)» (2010) авторы отмечали специфику трансформации законодательной политики Российской империи в отношении образования. Кроме этого они проанализировали вклад еврейских предпринимателей в развитие еврейской культуры в Забайкальском регионе.

В монографии «Еврейские общины Западной Сибири (XIX - начало XX в.)» (2013) Ю.М. Гончаров констатировал особенность положения еврейской общины Сибири, которая по ряду факторов, в том числе культурно-психологических, отличалась от иных еврейских общин Российской империи. Исследователь указывал, что это связано с процессом аккультурации, а также активным участием еврейского населения в общественной жизни сибирских городов.

B.Н. Шайдуров в монографии «Евреи, немцы, поляки в Западной Сибири XIX - начала XX в.» (2013) отмечал влияние улучшения экономического положения еврейского населения Сибири во второй XIX в. на развитие различных социальных институтов, связанных с образованием, благотворительностью, религиозной сферой и т.д.

В работе И.М. Шеиной (2014) обращалось внимание на специфику менталитета и культуры евреев в Сибири. Автор отмечала значительный уровень грамотности среди еврейского населения. Несмотря на то, что в Сибири общалось оно главным образом по-русски, изучение древнееврейского языка носило значимый характер.

Ряд трудов В.С. Сулимова (2013; 2014; 2017) посвящен рассмотрению развития школьного образования евреев в годы Первой мировой войны. Исследователь отмечал увеличение количества учеников-евреев в Сибири, чему способствовала законодательная политика того времени в отношении семей мобилизованных воинов.

Обращение многих исследователей к истории культурно-просветительского движения евреев в Сибири свидетельствует о значимости изучения данного феномена. Еврейское население как часть многонационального и поликонфессионального конгломерата смогло внести свой вклад в развитие общественного сознания, гражданской идентичности сибирского региона.

\section{ДЕЯТЕЛЬНОСТЬ ОПЕ В ТОМСКЕ (1891-1914 ГГ.)}

Согласно переписи населения 1897 г., в Томске проживало 52210 чел., из них - 3202 чел. исповедовали иудаизм (Первая Всеобщая перепись, 1904, с. 69). В начале XX в. в городе действовали три синагоги. По инициативе членов местной еврейской общины в Томске функционировали различные общественные учреждения: еврейское одноклассное училище (1874) для мальчиков 
с преподаванием на русском языке; «Дом призрения престарелых и бедных евреев имени И. и Л. Быховских» (1910); еврейский сиротский приют (1917) и т.д. В 1885 г. представителями томской еврейской общины была предпринята попытка открытия Томского еврейского благотворительного общества. Целью данной организации являлось оказание содействия нуждающимся евреям. Однако Устав организации не был утвержден МВД.

С 1891 г. в городе действовала касса ОПЕ. В ее функции входила организация сбора средств с целью передачи части сумм в центральный комитет общества, а также оказание финансовой поддержки учащимся-евреям Томска в виде выдачи ссуд на обучение. Пожертвования направлялись в кассу изо всех крупных населенных пунктов Сибири. За период с 1891 по 1905 гг. в Томскую кассу ОПЕ поступило 19369 руб. 69 коп. (Отчет, 1906, с. 9).

Открытию отделения ОПЕ в Томске препятствовало отсутствие необходимого количества членов, рекомендованных Уставом. В городе проживали три действительных члена, ежегодно вносившие по 25 руб. (П. С. Быховский, П. Л. Фуксман, контора «Бр. Бродские»), и четыре члена-благотворителя, вкладывавшие по 10 руб. Как отмечалось в статье газеты «Сибирская жизнь» за 17 марта 1898 г.: «Цифра, при многочисленности в Томске еврейского общества, довольно-таки ничтожная» (Томская касса, 1898. с. 3). В 1905 г. в Томске проживали три действительных члена (М. Р. Бейлин, И. С. Быховский, И. Л. Фуксман), 11 членов-благотворителей, 25членов-соревнователей; присяжный поверенный М. Р. Бейлин являлся уполномоченным ОПЕ.

По ходатайству ОПЕ, разрешение на открытие отдела в Томске было получено от Санкт-Петербургского градоначальника в начале 1910 г. Значительное снижение суммы взноса отразилось на увеличении количества пожелавших вступить в ряды членов нового отдела.

Первое общее собрание сотрудников Томского отдела ОПЕ состоялось 21 февраля 1910 г. На нем были избраны члены руководящего органа отдела - комитета. Место председателя занял М.Р. Бейлин, товарища председателя - врач М. О. Фуксман, секретарем стал помощник присяжного поверенного Н. Я. Левин, казначеем - зубной врач М. А. Лурия. В члены правления так же вошли Н.Г. Гинзберг (после его заменил доктор И. А. Янкелевич), раввин Б. И. Беры и А. М. Уманский. В январе 1911 г. при комитете организовали дамский кружок, который должен был оказывать всестороннее содействие Томскому отделения ОПЕ. В кружок вошли Е. Я. Анцелевич, О. Л. Каменецкая, Е. М. Лурия, Е. Я. Лурия и М. О. Цам (В еврейской общине, 1911, с. 3). 
Финансирование отдела осуществлялось за счет членских взносов, частных пожертвований, возвращении ссуд за обучение, средств, вырученных от проведения различных мероприятий (спектаклей, творческих вечеров и т.д.). От имени организации некоторым иногородним лицам были разосланы именные письма с просьбой о пожертвованиях. В результате из Владивостока от промышленника Л. С. Скидельского поступило 25 руб., а из Харбина от владельца мукомольных мельниц А. С. Патушинского - 15 руб., затем ему удалось собрать и передать в кассу отдела еще 96 руб. Общая сумма пожертвований в первый год работы Томского отдела ОПЕ составила 2283 руб. 45 коп. (Отчет, 1911, с. 11).

Сотрудники Томского отдела ОПЕ приняли решение о продолжении оказания финансовой поддержки учащимся. Во второй половине 1910 г. была внесена оплата за 10 студентов Томского университета, 21 студента Технологического института, 10 учениц женской гимназии, двух учеников ремесленного училища и т.д. Всего на учащихся-евреев в 1910 г. было израсходовано 2101 руб. (Отчет, 1911, с. 7).

Томский отдел ОПЕ выступил инициатором преподавания в некоторых учебных заведениях города закона еврейской веры. Помимо этого, сотрудники отдела планировали в ближайшее время открытие библиотеки имени раввина Б.И. Левина - видного общественного деятеля Томска.

В начале 1914 г. в Томском отделе ОПЕ прошли выборы членов комитета. Место председателя занял М. А. Каменецкий, товарища председателя - С. А. Анцелевич, казначея - доктор И. А. Янкелевич, секретаря - С. А. Лейбович. Членами комитета стали М. Р. Бейлин и А. Л. Серебров. Значительным событием в деятельности ОПЕ в первой половине 1914 г. явилось получение разрешения на открытие бесплатной библиотеки.

С началом Первой мировой войны ОПЕ пришлось столкнуться с необходимостью трансформации своей деятельности. Многих сотрудников учреждений ОПЕ мобилизовали на фронт. Помещения школы реквизировались для организации в них лазаретов. Из-за оккупации части территории Российской империи некоторые западные отделы ОПЕ были вынуждены свернуть свою деятельность. В августе 1914 г. в периферийные отделы ОПЕ разослали телеграммы с просьбами оказать финансовую поддержку учителям и ученикам, находящимся в местностях, пострадавших от военных действий. На общем собрании членов Томского отдела ОПЕ приняли решение о передаче в Петроград 500 руб. пожертвований (Отчет, 1915, с. 18). 
Во второй половине 1914 г. в деятельности Томского отдела ОПЕ наблюдается спад. В первую очередь это связано с уменьшением поступавших пожертвований, особенно от иногородних лиц. В 1914 г. открыли Иркутский отдел ОПЕ, комитет которого по понятным причинам был заинтересован в увеличении финансирования (Берман, 2020, с. 106).

В кассу общества перестали поступать деньги для погашения ссуд за обучение. Отсутствие свободных средств отразилось на реализации целей и задач, поставленных перед отделами ОПЕ. В начале марта 1915 г. члены Комитета Томского отдела ОПЕ в газете «Сибирская жизнь» опубликовали извещение, что в случае непогашения ссуды фамилия должника будет указана в списке, размещенном в российских газетах (Долг чести, 1915, с. 3). Ситуация с возвращением ссуд усугублялась тем, что многие лица, окончившие обучение были мобилизованы на фронт.

4 декабря 1914 г. в помещении общественного собрания члены Томского отдела ОПЕ устроили благотворительный вечер. Мероприятие состояло из двух отделений. В первом показали пьесу еврейского драматурга Я.М. Гордина «Любовь и смерть», а во втором провели музыкальный концерт. Общий доход от продажи входных билетов составил 550 руб. 93 коп., из них 137 руб. 74 коп. были перечислены в пользу больных и раненых воинов (Отчет, 1911, с. 4). В заметке в газете «Утро Сибири» от 6 декабря 1914 г. отмечалось, что данный вечер привлек мало внимания из-за отсутствия объявлений о мероприятии. В этом же выпуске поместили сообщение о проведении 7 декабря 1914 г. Томским отделом ОПЕ в «Доме призрения престарелых и бедных евреев имени И. и Л. Быховских» лекции И. С. Быховского «Бялик, характер и мотивы его поэзии».

\section{КУЛЬТУРНО-ПРОСВЕТИТЕЛЬНАЯ ДЕЯТЕЛЬНОСТЬ ТОМСКОГО ОТДЕЛА ОПЕ В 1915-1918 ГГ.}

Весной 1915 г. произошла смена членов правления Томского отдела ОПЕ. Место председателя занял И. С. Быховский, товарища председателя - М. Р. Бейлин, казначея - С. А. Анцелевич, секретаря А. С. Краскин. В мае 1915 г. сотрудниками отдела состояло 163 чел. (В обществе распространения просвещения среди евреев, 1915, с. 3).

В 1915 г. Томское отделение планировало сконцентрировать свою деятельность на культурно-просветительном направлении, цель которого заключалась в проведении лекций и литературных чтений для пропаганды еврейской культуры. Мероприятия (Табл. 1) проходили в помещении «Дома призрения престарелых и бедных 
евреев имени И. и Л. Быховских». Активное участие в культурнопросветительной деятельности принимала местная молодежь. В сентябре 1916 г. при Томском отделении ОПЕ была открыта специальная культурная секция, которая занималась организацией и проведением публичных выступлений.

\begin{tabular}{|c|c|c|}
\hline Дата & Название мероприятия & Лектор \\
\hline \multicolumn{3}{|c|}{1915} \\
\hline 11 января & $\begin{array}{l}\text { Доклад «Иудаизм и эллинизм в } \\
\text { поэзии Бялика и Черпиховского» } \\
\text { (1 часть) }\end{array}$ & раввин Б.И. Бер \\
\hline \multirow[t]{2}{*}{1 февраля } & $\begin{array}{l}\text { Доклад «Иудаизм и эллинизм } \\
\text { поэзии Бялика и Черпиховского» } \\
\text { (2 часть) }\end{array}$ & раввин Б.И. Бер \\
\hline & Чтение пьесы Т. Герцля «Доктора» & \\
\hline 12 апреля & $\begin{array}{l}\text { Собеседование, посвященное } \\
\text { творчеству писателя Л. Перетца }\end{array}$ & $\begin{array}{l}\text { Н.Я. Самородницкий } \\
\text { С.А. Кабалкин }\end{array}$ \\
\hline 18 апреля & $\begin{array}{l}\text { Доклад «Библейский период } \\
\text { еврейской истории» }\end{array}$ & Колтунов \\
\hline \multirow[t]{2}{*}{15 ноября } & $\begin{array}{l}\text { Доклад «Еврейская история как } \\
\text { источник национального } \\
\text { самосознания» }\end{array}$ & И.С. Быховский \\
\hline & $\begin{array}{l}\text { Музыкальные номера и } \\
\text { художественное чтение рассказов } \\
\text { Шолом-Алейхема }\end{array}$ & \\
\hline \multirow[t]{2}{*}{19 декабря } & $\begin{array}{l}\text { Доклад «О причинах } \\
\text { антисемитизма» }\end{array}$ & Л. Зунделевич \\
\hline & $\begin{array}{l}\text { Литературное чтение рассказов } \\
\text { Шолом-Алейхема }\end{array}$ & Могун \\
\hline \multirow[t]{4}{*}{20 декабря } & $\begin{array}{l}\text { Торжественное чествование в } \\
\text { честь } 80 \text {-летия писателя Ш. } \\
\text { Абрамовича }\end{array}$ & $\begin{array}{l}\text { Вступительная речь И.С. } \\
\text { Быховского }\end{array}$ \\
\hline & $\begin{array}{l}\text { Доклад «О жизни и творчестве } \\
\text { Абрамовича» }\end{array}$ & М.С. Гуревич \\
\hline & $\begin{array}{l}\text { Доклад «Ш.Я. Абрамович как } \\
\text { гражданин» }\end{array}$ & М.К. Амдурский \\
\hline & $\begin{array}{l}\text { Литературное чтение отрывков их } \\
\text { произведений Ш. Абрамовича; } \\
\text { музыкальные номера }\end{array}$ & \\
\hline
\end{tabular}




\section{6}

14 февраля

13 марта

11 сентября

18 сентября

9 октября

13 ноября

15 января
8 января
Собеседование «"Пророки” и писатель Перец»

Номера еврейской народной музыки

Собеседование «Эпоха

просвещения максимализма»

Номера еврейской народной музыки

Литературное собеседование в память С.Г. Фруга и ШоломАлейхема

Доклад по истории самообразования еврейской молодежи и обсуждение его

Доклад «Раби Акиба и его эпоха»

Литературное отделение: чтение стихов Х.Н. Беляка и С.Г. Фруга

Вечер памяти С.Г Фруга

Доклад «С.Г. Фруг - певец

Возрождения»

Литературное чтение

произведений С.Г. Фруга на

разговорно-еврейском и русском

языках

Музыкально-вокальное отделение

Доклад «Маймонид и его литературное творчество»

Литературное чтение

стихотворений С.Г. Фруга и

Беляка

Концерт
Вступительная речь М.P. Бейлина

И.С. Быховский

г-жа Ш., г-н В.

И. Вильскер

раввин М.Ш. Певзнер

\section{7}

Доклад «Евреи в Финляндии» (по М.К. Амдурский литературным источникам)

Литературное чтение произведений Шолом-Алейхема и С.Г. Фруга

Вечер памяти врача Л.С. Пинскера

Доклад «Л.С. Пинскер»

А.Е. Евзеров

Доклад «У могилы Л.С.

Пинскера»
М.К. Амдурский 


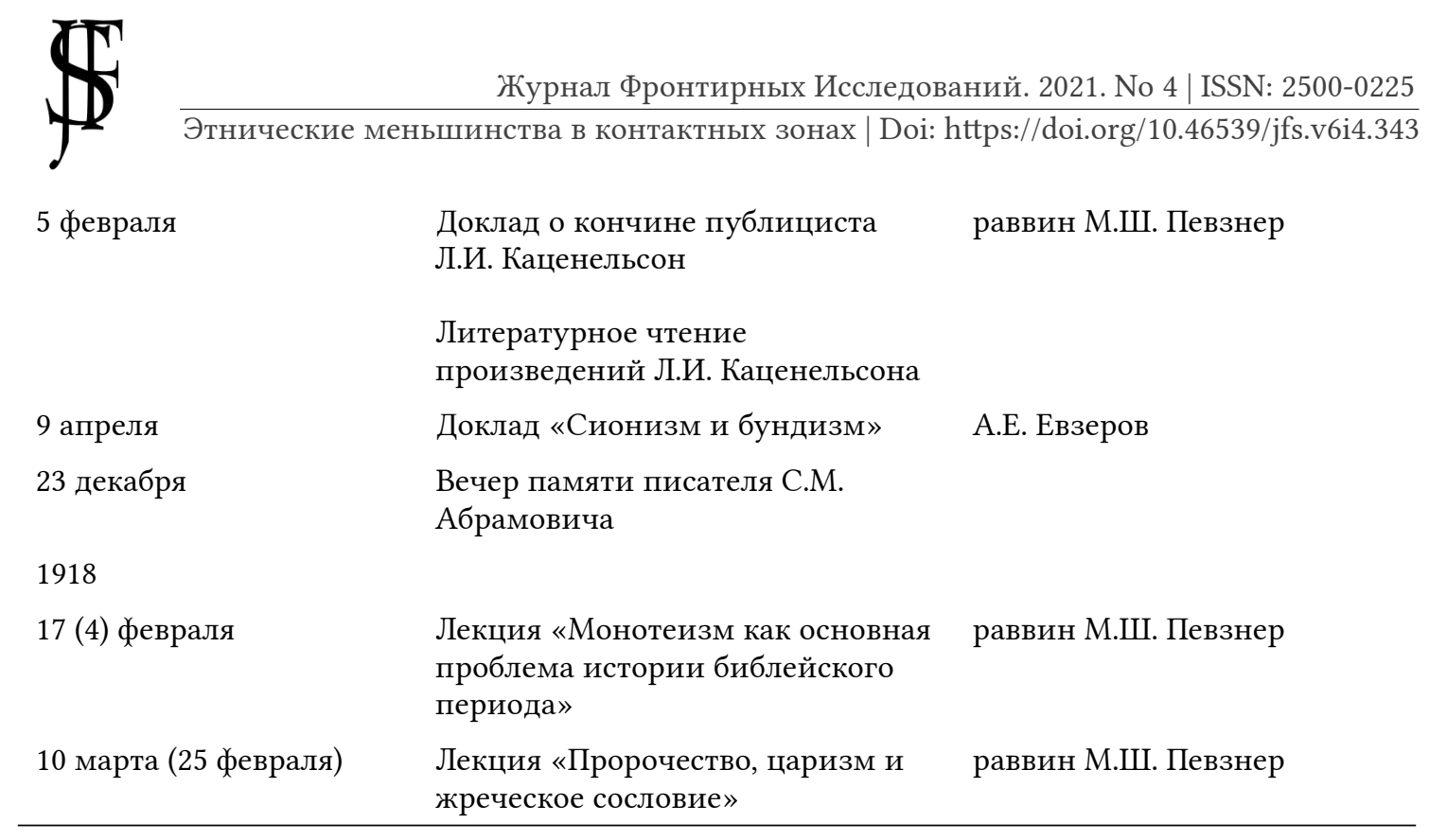

Таблица 1. Избранные культурно-просветительные мероприятия Томского отдела ОПЕ за 1915-1918 гг. (по материалам периодической печати «Сибирская жизнь» и «Утро Сибири»)

Table 1. Selected cultural and educational activities of the Tomsk department of the SEJ in 1915-1918. (According to the periodicals "Sibirskaya Zhizn" and "Utro Sibiri")

Довольно хорошо зарекомендовала себя работа бесплатной библиотеки. В мае 1915 г. в ней начитывалось 1082 книги на русском, древнееврейском и «народном» языках. В библиотеку был записан 41 человек. Как отмечали сотрудники Томского отдела ОПЕ, небольшое количество читателей было связано с «... недостаточным количеством книг и отсутствие русских авторов» (В обществе распространения просвещения среди евреев, 1915, с. 3). Однако к концу 1915 г. фонд библиотеки увеличился до 1267 единиц.

В 1915 г. в ведение Томского отдела ОПЕ перешла детская еврейская колония. Ранее ежегодное попечительство над учреждением принимал доктор И.А. Янкелевич. Практика открытия летних колоний для учащихся широко распространялась среди отделов ОПЕ (Перзнер, 2020, с. 299). Главной задачей таких досуговых организаций являлось развитие физических и творческих способностей ребенка. Детская еврейская колония в Степановке работала с 20 мая по 20 июня 1915 г. Всего было принято 92 ребенка. Самую многочисленную группку составили дети 10 летнего возраста. Первоначально на содержание колонии в летнем сезоне 1915 г. выделили 655 руб. (В обществе распространения просвещения среди евреев, 1915, с. 3). В конечном счете на колонию было истрачено 1125 руб. 
Работа детской еврейской колонии осуществлялась и в последующие годы. Одной из главных проблем функционирования стало отсутствие квалифицированного педагогического персонала, который мог бы координировать работу учреждения.

\section{УЧАСТИЕ ТОМСКОГО ОТДЕЛА ОПЕ В РАБОТЕ С БЕЖЕНЦАМИ-ЕВРЕЯМИ}

В связи с оккупацией западных территорий Российской империи многие евреи были вынуждены покинуть свои родные места, направились в тыл страны.

В начале 1915 г. Томский отдел ОПЕ провел мероприятия с целью сбора средств в пользу пострадавших евреев. Так, 14 февраля 1915 г. в общественном собрании состоялся благотворительный вечер. На мероприятии были показаны балет-пантомима «Эсфирь» и спектакль по пьесе Шолом-Алейхема «Доктор». При участии артистов Мельниковой и Сычева в конце вечера прошло «разнохарактерное кабаре». По предварительному подсчету членов Томского отдела ОПЕ удалось выручить 1300 руб. (Штемпель, 1915, с. 3).

Массовые потоки беженцев начали прибывать в Томск с сентября 1915 г. Осенью 1915 г. в городе было зафиксировано 396 евреев (ГАТО, n.d., Ф. 1. Оп. 1. Д. 48. Л. 41). Уже к 1 июля 1916 г. из 3986 зарегистрированных в городе беженцев, 667 были евреи (ГАТО, n.d., Ф. 1. Оп. 1. Д. 5. Л. 42).

С сентября 1915 г. в Томске действовал местный отдел петроградской организации Еврейского комитета помощи жертвам войны (ЕКОПО). Целью деятельности организации являлось всестороннее содействие еврейскому населению Российской империи, пострадавшему от военных действий. В состав Томского отдела ЕКОПО вошли видные члены еврейской общины, которые совмещали работу в нескольких учреждениях. Председателем отдела был избран М. Р. Бейлин, товарищами председателя - М. И. Шкундин и А. С. Самкин. Членами комитета стали И.С. Быховский (по совместительству председатель Томского отдела ОПЕ) и Н.К. Фельдштейн (В еврейском о-ве, 1916, с. 5). Сотрудники организации занимались вопросами расселения, выплатой денежных субсидий, оказанием медицинской поддержки, трудоустройством и т.д. беженцев-евреев в Томске. Разносторонняя деятельность учреждения требовала значительных человеческих и финансовых ресурсов. Непосредственным участием в вопросах, связанных с просвещением и образованием беженцев-евреев, занимались члены местного отдела ОПЕ. 


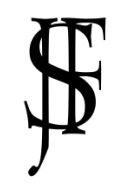

Журнал Фронтирных Исследований. 2021. No 4 | ISSN: 2500-0225

Этнические меньшинства в контактных зонах | Doi: https://doi.org/10.46539/jfs.v6i4.343

Главной трудностью для прибывавших в Сибирь евреев являлось плохое знание русского языка (Ульянова, 2011, с. 52). Это приводило к сложностям в коммуникации с местным населением. Помимо этого, среди беженцев старше 8 лет был высокий процент малограмотных и неграмотных, как среди говорящих на русском, так и еврейском языках. Данные проблемы негативно сказывалась на бытовой жизни беженцев-евреев, особенно при трудоустройстве.

Основной процент прибывавших евреев составляли люди в возрасте от 13 до 42 лет - группа, наиболее интегрированная в общественную жизнь; однако в связи с вышеуказанными факторами требовавшая большого внимания в вопросах адаптации. Томский отдел ОПЕ принял на себя заботы, связанные с вопросами образования среди беженцев-евреев.

В декабре 1915 г. отдел объявил об открытии курсов для беженцевевреев старше 16 лет. Основу программы составили общеобразовательные предметы, еврейская и русская истории, древнееврейский язык, чтение и письмо. За первые три месяца работы обучались 50 слушателей.

В начале лета 1916 г. члены Томского отдела ОПЕ направили ходатайство в Дирекцию Западных училищ Томской губернии об открытии двухгодичных курсов для взрослых евреев в возрасте от 17 лет. Основное внимание предполагалось уделять изучению русского языка; планировалось чтение и перевод на него ряда ветхозаветных книг («Книга Бытия», «Книга Судеб», «Второзаконие» и т.д.). Заведующим курсами был избран зубной врач М. А. Каменецкий (ГАТО, n.d., Ф. 3. Оп. 67. Д. 462. Л. 2об.).

Особо важным сотрудники Томского отдела ОПЕ считали образование беженцев-евреев младшей школьной группы (т.е. в возрасте от 7 до 12 лет). В городе действовало еврейское училище для мальчиков, но оно не могло принять всех желающих. На общем заседании членов местных отделов ЕКОПО и ОПЕ летом 1916 г. было принято решение об открытии смешанного училища без преподавания на идише. В учебное заведение приглашали детей-евреев не только из числа беженцев, но и из местного населения (Кутилова и др., 1999, с. 86). Заведующим учебным заведением был Альщиц. Финансирование осуществлялось за счет средств Центрального отдела ОПЕ. Денежное содействие оказывал и местный отдел ЕКОПО. В 1917 г. в школе обучалось 60 детей. Программа училища носила общеобразовательный характер.

В годы Первой мировой войны Томский отдел ОПЕ продолжил оказание финансовой помощи учащимся-евреям. Особенно это стало 
актуально в связи с ростом числа беженцев и снижением интенсивности устремлений властей Российской империи по принятию евреев в учебные заведения. В августе 1916 г. Е.И. Фуксман передала Томскому отделу ОПЕ квитанцию на неприкосновенный вклад в 7500 руб. с просьбой потратить проценты от этих денежных средств на стипендии для евреев, обучающихся в гимназиях и высших учебных заведениях Томска (Стипендия при обществе еврейского просвещения, 1916, с. 3). Стипендии учреждались в память Б. Л., В. Б. и Р. Б. Фуксман.

\section{РЕЗУЛЬТАТЫ}

Томский отдел ОПЕ - одно из старейших общественных объединений евреев в Сибири. На протяжении многих лет организация оказывала содействие местным учащимся-евреям. Наибольший пик активности Томского отдела ОПЕ выпал на годы Первой мировой войны. На это повлияли как внутренне факторы развития учреждения, так и военное положение. Отдаленность Томска от центра, а также специфика проживания евреев в Сибири отражались на функционировании периферийного отдела.

Деятельность Томского отдела ОПЕ в годы Первой мировой войны развивалась по двум направлениям - культурно-просветительном и благотворительном. Благотворительное направление ограничивалось преимущественно сбором средств на оказание помощи пострадавшим евреям с западных территорий Российской империи. Культурнопросветительная деятельность заключалась в проведении ряда мероприятий по пропаганде еврейской истории и культуры. Значительное количество таких мероприятий (табл. 1) свидетельствовало о большом интересе со стороны томской общественности. Проводимые членами ОПЕ лекции затрагивали актуальные для того времени темы, например, бундизм. Кроме этого, сотрудники учреждения обращали внимание на культурное и физическое развитие детей. Томский отдел ОПЕ принял на себя заботу о работе детской еврейской колонии.

Согласно статистическим данным, значительное число прибывавших беженцев-евреев были неграмотными или малограмотными, а также плохо владели русским языком, что осложняло процесс их адаптации. Томский отдел ОПЕ занялся организацией специальных курсов для взрослых беженцев-евреев. Специально для вынужденных мигрантов школьного возраста было открыто смешанное училище.

Томский отдел ОПЕ существовал преимущественно на пожертвования, поступавшие от представителей еврейских общин Сибири и Дальнего Востока. Однако такое финансирование не было стабильным, особенно в годы Первой мировой войны. Организация стремилась 
к расширению своей деятельности и поиску дополнительных источников пополнения средств.

Центральный отдел ОПЕ в Петрограде был закрыт в 1918 г., но некоторые периферийные отделы, в том числе Томский, продолжили свою деятельность и в первые годы советской власти (Гончарова, 2007, с. 78).

\section{БЛАГОДАРНОСТИ}

Исследование выполнено при финансовой поддержке РФФИ в рамках научного проекта № 19-39-60009

\section{Список литературы}

Абросимова, Е. А. (1992). История законодательного регулирования создания и деятельности российских благотворительных организаций. Известия высших учебных заведений. Правоведение, (6), 89-94.

Белых, Е. А., Кальмина, Л. В. \& Курас, Л. В. (2005). Общественная и культурно-просветительская деятельность еврейских общин на территории Забайкальской области: 60-е гг. XIX в. - февраль 1917 г. Улан-Удэ: Восточно-Сибирская государственная академия культуры и искусств.

Берман, Е. А. (2020). Участие членов иркутской еврейской общины в работе Еврейского историко-этнографического общества (1909-1914 гг.). Этнография, 8(2). doi: 10.31250/2618-8600-2020-2(8)-103-116

В еврейской общине (1911). Сибирская жизнь, (22).

В еврейском о-ве (1916). Сибирская жизнь, (46).

В обществе распространения просвещения среди евреев (1915). Утро Сибири, (115).

Гончаров, Ю. М. (2013). Еврейские общины Западной Сибири (XIX - начало XX в.). Барнаул: АзБука.

Гончарова, Е. З. (2007). Деятельность «Общества для распространения просвещения между евреями в России» в Томске на рубеже XIX-XX веков (по материалам периодической печати). Евреи в Сибири и на Дальнем Востоке: история и современность: материаль VIII региональной научно-практической конференции (19-20 ноября 2007 года), 67-82. Красноярск.

Государственный архив Томской области (ГАТО) (б. д.). Ф. 1. On. 1. Д. 5; Ф. 1. On. 1. Д. 48; Ф. 3. On. 67. Д. 462.

Дегальцева, Е. А. (2006). «Общество для распространения просвещения между евреями в России» (1863-1929) как интеллектуальный центр национальной идентификации. Вестник Новосибирского государственного университета. Серия: История, филология, 5(1), 88-90.

Долг чести. (1915). Сибирская жизнь, (55). 
Егоров, В. В. (2013). Политика правительства Александра II в сфере образования российских евреев во второй половине XIX века. Мир политики и социологии, (12), 53-57.

Кнорринг, В. В. (2005). Издательская деятельность Общества для распространения просвещения между евреями в России (PhD Thesis). Санкт-Петербургский государственный университет культуры и искусств, Санкт-Петербург.

Кутилова, Л. А., Нам, И. В., Наумова, Н. И. \& Сафонов, В. А. (1999). Национальные меньшинства Томской губернии. Хроника общественной и культурной жизни. 1885-1919. Томск: Издательство Томского университета.

Отчет. (1914). Сибирская жизнь, (276).

Отчет Томской кассы Общества для распространения просвещения между евреями в России за 1905 г. (1906). Томск: Типо-литография К.Я. Зеленского.

Отчет Томской кассы Общества для распространения просвещения между евреями в России за 1910 г. (1911). Томск: Типо-литогр. Сибирск. Т-ва Печатн. Дела.

Отчет Томской кассы Общества для распространения просвещения между евреями в России за 1914 г. (1915). Томск: Типо-литогр. Сибирск. Т-ва Печатн. Дела.

Отчет Томской кассы Общества для распространения просвещения между евреями в России за 1915 г. (1916). Томск: Типо-литогр. Сибирск. Т-ва Печатн. Дела.

Певзнер, Е. Г. (2020). О деятельности летних детских колоний под покровительством Общества для распространения просвещения между евреями в России (ОПЕ). Евреи в мировой истории, культуре и политике, 299-304. Санкт-Петербург.

Первая Всеобщая перепись населения Российской империи 1897 г. Томская губерния. (1903). Санкт-Петербург: Типография Сиб. акц. общ. и писчебум. дела в России «Слово».

Стипендия при обществе еврейского просвещения. (1916). Сибирская жизнь, (171).

Сулимов, В. С. (2013). Прием евреев в школы Западной Сибири в период первой мировой войны. Евреи в социокультурном пространстве Тюмени и региона: к 100-летию тюменской синагоги, 65-69. Тюмень.

Сулимов, В. С. (2014). Вопросу о приеме евреев в школы Западной Сибири в годы Первой мировой войны. Материаль VII региональной научно-практической конференции «Вагановские чтения», посвященной 420-летию со дня основания 2. Тара (2. Тара, 14-15 марта 2014 года), 55-59. Омск.

Сулимов, В. С. (2017). Евреи в школах Западной Сибири. Конеи XIX - начало XX века. Тобольск.

Томская касса Общества для распространения просвещения между евреями России (1898). Сибирская жизнь, (60).

Ульянова, О. С. (2010). Еврейская община города Томска: Становление, развитие и свертывание ее деятельности. Томск: Издательство Томского университета.

Устав Общества для распространения просвещения между евреями в России. (1896). Москва: Русское Т-во печатн. и издательск. дела. 
Устав Общества для распространения просвещения между евреями в России (1908). Санкт-Петербург: Тиография И. Флейтмана.

Шайдуров, В. Н. (2013). Евреи, немиь, поляки Западной Сибири XIX - начала XX в. Санкт-Петербург: Издательство Невского института языка и культуры.

Шеина, И. М. (2014). Особенности менталитета и культуры еврейского населения Сибири в XIX в. Евреи Европы и Ближнего Востока: история, социология, культура: материаль Международной научной конференции, 27 апреля 2014 г., 163-167. Санкт-Петербург: Петербургский институт иудаики.

Шиловский, М. (2017). Первая мировая война 1914-1918 годов и Сибирь. Litres.

Штемпель. Еврейский вечер в пользу беженцев. (1915). Утро Сибири, (36).

\section{References}

Abrosimova, E. A. (1992). History of Legislative Regulation of Creation and Activity of Russian Charitable Organizations. Proceedings of Higher Education Institutions. Jurisprudence, (6), 89-94. (In Russian).

Belykh, E. A., Kalmina, L. V. \& Kuras, L. V. (2005). Social, cultural and educational activities of Jewish communities in Transbaikal Region: The 60s of the 19th century - February 1917. Ulan-Ude: East Siberian State Academy of Culture and Arts. (In Russian).

Berman, E. A. (2020). Participation of members of the Irkutsk Jewish community in the work of the Jewish Historical and Ethnographic Society (1909-1914). Ethnography, 8(2). doi: 10.31250/2618-8600-2020-2(8)-103-116 (In Russian).

Charter of the Society for the Dissemination of Education among Jews in Russia. (1896). Moscow: Russian Association of Printing and Publishing. (In Russian).

Charter of the Society for the Dissemination of Education among Jews in Russia. (1908). St. Petersburg: Tiography by I. Fleitman. (In Russian).

Degaltseva, E. A. (2006). Society for the Dissemination of Education among Jews in Russia (1863-1929) as an intellectual center of national identity. Bulletin of Novosibirsk State University. Series: History, Philology, 5(1), 88-90. (In Russian).

Duty of Honor. (1915). Siberian Life, (55). (In Russian).

Egorov, V. V. (2013). The Policy of Alexander II's Government on the Education of Russian Jews in the Second Half of the 19th Century. The World of Politics and Sociology, (12), 53-57. (In Russian).

First General Population Census of the Russian Empire 1897 Tomsk Province. (1903). St. Petersburg: Typography of the Siberian Acc. and Letterpress Society in Russia Slovo. (In Russian).

Goncharov, Y. M. (2013). Jewish Communities in Western Siberia (19th - early 20th centuries). Barnaul: AzBuka. (In Russian).

Goncharova, E. Z. (2007). Activities of the Society for the Education of Jews in Russia in Tomsk at the turn of the nineteenth and twentieth centuries (based on periodicals). Jews in Siberia and the Far East: History and Modernity: Materials of 
the VIII Regional Scientific-Practical Conference (19-20 November 2007), 67-82. Krasnoyarsk. (In Russian).

In Jewish society. (1916). Siberian Life, (46). (In Russian).

In the Jewish community. (1911). Siberian Life, (22). (In Russian).

In the Society for the Dissemination of Jewish Education. (1915). Siberian Morning, (115). (In Russian).

Knorring, V. V. (2005). Publishing activities of the Society for the Dissemination of Education among Jews in Russia (PhD Thesis). St. Petersburg State University of Culture and Arts, St. Petersburg. (In Russian).

Kutilova, L. A., Nam, I. V., Naumova, N. I. \& Safonov, V. A. (1999). National minorities of Tomsk province. Chronicle of Social and Cultural Life. 1885-1919. Tomsk: Tomsk University Press.

Pevzner, E. G. (2020). On the activities of summer children's colonies under the patronage of the Society for the Dissemination of Education among Jews in Russia (SPE). Jews in World History, Culture, and Politics, 299-304. Санкт-Петербург. (In Russian).

Postmark. Jewish evening for the benefit of refugees (1915). Siberian Morning, (36). (In Russian).

Report of the Tomsk Fund of the Society for the Enlightenment of Jews in Russia for 1905 (1906). Tomsk: Printing and Lithography of K.Ya.. (In Russian).

Report of the Tomsk Fund of the Society for the Enlightenment of Jews in Russia for 1910 (1911). Tomsk: Printing and Lithography of K.Ya. (In Russian).

Report of the Tomsk Fund of the Society for the Enlightenment of Jews in Russia for 1914 (1915). Tomsk: Siberian Printing Company Typolithography. (In Russian).

Report of the Tomsk Fund of the Society for the Enlightenment of Jews in Russia for 1915 (1916). Tomsk: Siberian Printing Company Typolithography. (In Russian).

Report (1914). Siberian Life, (276). (In Russian).

Scholarship from the Society for Jewish Education. (1916). Siberian Life, (171). (In Russian).

Shaidurov, V. N. (2013). Jews, Germans, and Poles in Western Siberia in the 19th and early 20th centuries. St. Petersburg: Publishing house of the Nevsky Institute of Language and Culture. (In Russian).

Sheina, I. M. (2014). Peculiarities of Mentality and Culture of the Jewish Population of Siberia in the 19th Century. Jews of Europe and the Middle East: History, Sociology, Culture: Proceedings of the International Scientific Conference, April 27, 2014, 163-167. St. Petersburg: St. Petersburg Institute of Jewish Studies. (In Russian).

Shilovsky, M. (2017). World War I 1914-1918 and Siberia. Litres. (In Russian).

State Archive of the Tomsk Region. (n. d.). F. 1. In. 1. C. 5; F. 1. In. 1. C. 48; F. 3. In. 67. C. 462. (In Russian). 
Sulimov, V. S. (2013). Admission of Jews to Schools in Western Siberia during World War I. Jews in the Socio-Cultural Space of Tyumen and the Region: Toward the 100th Anniversary of the Tyumen Synagogue, 65-69. Тюмень. (In Russian).

Sulimov, V. S. (2014). The Question of the Admission of Jews to Schools in Western Siberia during World War I. Materials of the VII regional scientific-practical conference "Vaganovsky readings" dedicated to the 420th anniversary of the city of Tara (Tara, March 14-15, 2014), 55-59. Омск. (In Russian).

Sulimov, V. S. (2017). Jews in the schools of Western Siberia. Late 19th-early 20th century. Tobolsk. (In Russian).

Tomsk Fund of the Society for the Dissemination of Education among the Jews of Russia (1898). Siberian Life, (60). (In Russian).

Ulyanova, O. S. (2010). Jewish community of Tomsk: Formation, Development, and Curtailment of its Activities. Tomsk: Tomsk University Press. (In Russian). 